\title{
Analysis of trimaran-pentamaran side hull location based on clearance and staggers with stern form variations
}

\author{
Yanuar $^{1, *}$, Wiwin Sulistyawati ${ }^{1}$, R. Joshua Yones $^{1}$, and Samodero Mahardika ${ }^{1}$ \\ ${ }^{1}$ Department of Mechanical Engineering, Universitas Indonesia, Depok 16424, Indonesia
}

\begin{abstract}
An optimum design of ship is to achieve the required speed with minimum power requirements. On multihull, sidehull position against to mainhull influences the friction resistance and its stability. Frictional resistance of multi-hull increases due to the addition of wetted surface area of hull, but wave making resistance can be lowered by a slender hull form. This research are experimental tests of trimaran with five Wigley hulls on a combination transom and without transom. The test varied on stagger, clearance and trim at several speeds. A ship with formation arrow tri-hull on forward was given to prove the resistance reduction due to cancellation wave which was indicated by negative interference. The influence diverse position of sidehull has shown that model non-transom (NT) stern moreover give beneficial resistance than model with transom (WT) at high speed. Similarly, in the trim conditions that NT more favorable on trim specifically for high speed depending on the position of the sidehull to the mainhull.
\end{abstract}

\section{Introduction}

Multihull remains an interesting subject for some marine applications even in the next few years. They have been widely applied in high-speed transport with good hydrodynamic performance, larger deck areas and excellent stability characteristics.

All possibilities in reducing resistance of multi-hull ships by slenderness shape of hull and its placement. Several studies had proved multihull besides influence of mainhull form parameters, also variable factors from sidehull and its relative position to mainhull. Sidehull position against to mainhull influences the friction resistance and its stability [1]. Frictional resistance of multi-hull increases as a result of the addition of wetted surface area of hull, but wave making resistance can be lowered by a slender hull form. [2] indicates that decreases of the wave resistance and increased of the friction resistance is influenced by the ratio of length to width $(\mathrm{L} / \mathrm{B})$ due to viscous factor. Moreover, the influence of viscosity on the hydrodynamic of multihull more analyze by [3]. Then [4] with comparison of experimental and theoretical approach on investigation of multihull (catamaran) hull clearance. Furthermore, deeper expression by [5] studied on effects of clearance of between hull on resistance, trim and discussion on longitudinal wave cuts.

The slender hull as known as Wigley (parabolic hull) from research by [6] on catamaran, trimaran, quadrimaran (tetramaran) and pentamaran. As well as [7] - [12] by determining the configuration of multihull on optimum distance of Wigley hull such as: catamaran, trimaran and tetramaran, with and without longitudinal of stagger. The studies of configurations of Wigley hull form on multihull has been proven effective in resistance deduction. And here used a variation of transom stern on mainhull and sidehull to know the resistance characteristic, especially its effect on wave resistance. Other research has concerned a transom stern hull, such as [13] showed favorable resistance characteristics at high speeds, which give a significant influence on the wave resistance and wave wash. And [14] had obtained the best clearance and stagger on multihull with variation transom stern to enhance the interference effect and reflected wave patterns.

Aim of this study is experimental studies on trimaran-pentamaran using wigley hullform to obtain staggered configuration, clearance and trim with combination of stern with transom and without transom.

\section{Experimental tests}

This research use trimaran with five hulls, outrigger will be varied on stagger and clearance. An experimental tensile test based on the ITTC.

\subsection{Models characteristics}

The design of pentamaran was not an ordinary pentamaran design with five hulls of same dimensions connected transversally. Here It like a trimaran with each of the side of the main hull consists of 2 side hulls. The parameters of the pentamaran are given in Table 1 and within its lines plan are sketched in figure 1 and 2 . Which Figure 1 is design of pentamaran describe main

Corresponding author: yanuar@eng.ui.ac.id 
hull with transom stern and variation side hulls: transom stern on front and no transom on after.
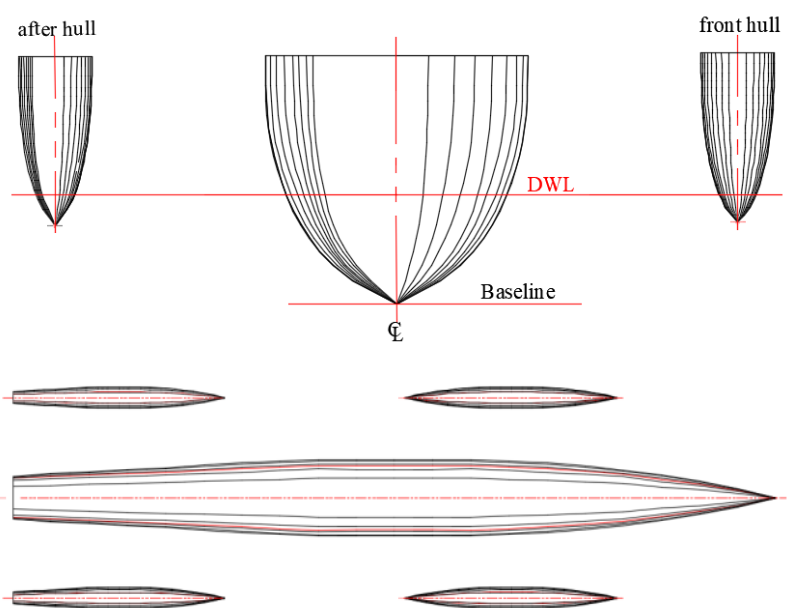

Fig.1. Set up trimaran-pentamaran configuration with transom on both mainhull and after hull of sidehull as WT model (with transom)
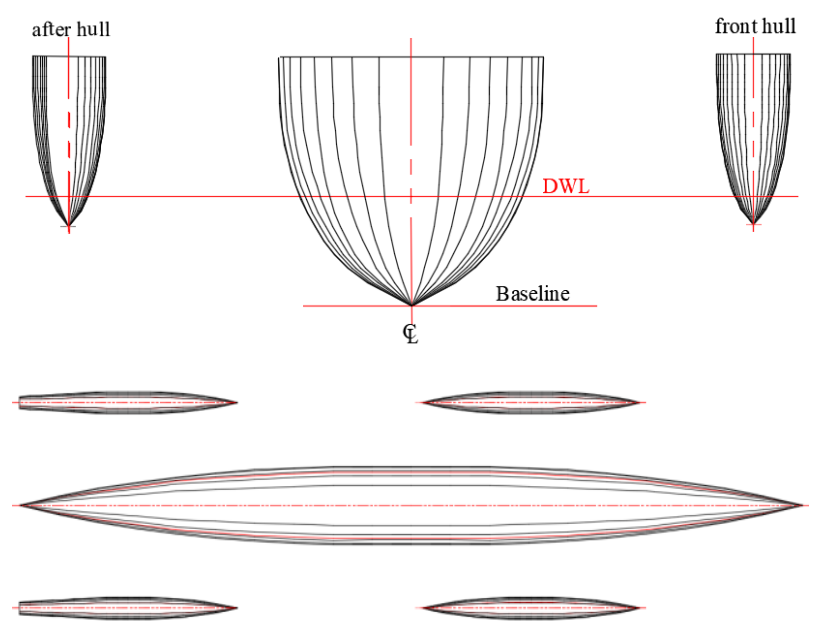

Fig.2. Set up trimaran-pentamaran configuration no transom as NT model (no transom)

\subsection{Positioning}

Model experiments were developed to allow some configurations regarding of resistance components and trim. Variations position of stagger are 0.35 and 0.40 , is ratio of distance of stern mainhull to stern of after sidehull to mainhull length. As for variation position of clearance, among others, $1.05,1.20,1.35,1.50$, is ratio of distance centerline of mainhull to centerline of sidehull to mainhull width. Detail of name models experiment and configuration of both WT model (with transom) and NT model (no transom) are shown in Table 2.

Table 2. Model names and configurations

\begin{tabular}{|c|c|c|}
\hline Model & Stagger & Clearance \\
\hline $\mathrm{WT} /$ NT 1 & $0.35 \mathrm{~L}$ & $1.05 \mathrm{~B}$ \\
\hline $\mathrm{WT} /$ NT 2 & $0.35 \mathrm{~L}$ & $1.20 \mathrm{~B}$ \\
\hline $\mathrm{WT} /$ NT 3 & $0.35 \mathrm{~L}$ & $1.35 \mathrm{~B}$ \\
\hline $\mathrm{WT} / \mathrm{NT} 4$ & $0.35 \mathrm{~L}$ & $1.50 \mathrm{~B}$ \\
\hline $\mathrm{WT} /$ NT 5 & $0.40 \mathrm{~L}$ & $1.05 \mathrm{~B}$ \\
\hline $\mathrm{WT} /$ NT 6 & $0.40 \mathrm{~L}$ & $1.20 \mathrm{~B}$ \\
\hline $\mathrm{WT} /$ NT 7 & $0.40 \mathrm{~L}$ & $1.35 \mathrm{~B}$ \\
\hline $\mathrm{WT} / \mathrm{NT} 8$ & $0.40 \mathrm{~L}$ & $1.50 \mathrm{~B}$ \\
\hline
\end{tabular}

\subsection{Experimental set-up}

The experiment test was constructed in water tank of 50 $\mathrm{m}$ length, $10 \mathrm{~m}$ width, and $2 \mathrm{~m}$ depth of Universitas Indonesia related to various instruments; set of DAQ, voltage regulator, electric motor, load cell, speed marker and computer for data acquisition. The inhibitory dynamometer shall measure horizontal tensile strength with a tolerance $0.2 \%$ or $0.05 \mathrm{~N}$ of the maximum capacity of the dynamometer measurements whichever is greater.

The model (Fig. 3) was tested in calm water, in accordance to International Towing Tank Conference (ITTC) 1978, components of calm-water ship resistance. And Its configurations have been performed at the different of hull separation reported in Table 2. Here was analyzed various configurations and trims on speed range corresponds to Froude numbers between 0.4 and 0.7 . The test is investigated the influence transom and trim angle on $0^{0} ; 0,5^{\circ} ; 1,0^{0}$. Which the trim will be done after gets the best configuration (minimum resistance) of stagger and clearance.

Table 1. The parameters of the trimaran-pentamaran

\begin{tabular}{|l|c|c|c|c|}
\hline \multicolumn{1}{|c|}{ Parameter } & $\begin{array}{c}\text { Mainhull } \\
\text { with transom }\end{array}$ & $\begin{array}{c}\text { Mainhull } \\
\text { no transom }\end{array}$ & $\begin{array}{c}\text { Sidehull } \\
\text { with transom }\end{array}$ & $\begin{array}{c}\text { Sidehull } \\
\text { no transom }\end{array}$ \\
\hline Length over all $(\mathrm{LOA}) \mathrm{m}$ & 1.8 & 1.8 & 0.5 & 0.5 \\
\hline Breadth $(\mathrm{B}) \mathrm{m}$ & 0.18 & 0.18 & 0.05 & 0.05 \\
\hline Height $(\mathrm{H}) \mathrm{m}$ & 0.17 & 0.17 & 0.12 & 0.12 \\
\hline Draft $(\mathrm{T}) \mathrm{m}$ & 0.08 & 0.08 & 0.03 & 0.03 \\
\hline Block coefficient $(\mathrm{cb})$ & 0.5 & 0.46 & 0.45 & 0.42 \\
\hline Displacement $(\Delta) \mathrm{kg}$ & 11.46 & 10.48 & 0.223 & 0.213 \\
\hline Wetted surface area $\mathrm{m}^{2}$ & 0.38 & 0.37 & 0.033 & 0.033 \\
\hline
\end{tabular}




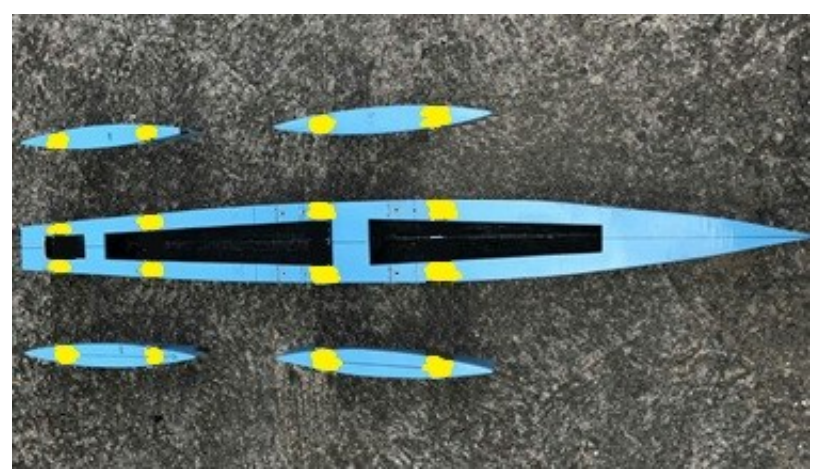

Fig.3. Experiment model

\section{Hydrodynamic}

The direct resistance resulting of contributions from the fluid viscosity $\left(R_{V}\right)$, and wave resistance $\left(R_{W}\right)$, which can be expressed as

$$
\begin{gathered}
R_{T}=R_{V}+R_{W} \\
R_{T}=(1+k) R_{F}+R_{W}
\end{gathered}
$$

where $R_{T}$ is total resistance considered to summation of wave resistance $R_{W}$, influence from viscosity, $R_{V}$, and wave-pattern generation. While itself of the viscosity is the embodiment of friction drag $\mathrm{R}_{\mathrm{F}}$ and form factor $\mathrm{k}$, which obtained by Prohaska's method from low-speed measurements.

The evaluation of the total resistance to the results of experiment is expressed in total resistance coefficients, defined as

$$
C_{T}=R_{T} / \frac{1}{2} \rho V^{2} S
$$

which frictional drag coefficient $\mathrm{C}_{\mathrm{F}}$ is calculated from ITTC 1957 correlation line formula and the wave drag coefficient $\mathrm{C}_{\mathrm{W}}$ obtained after both of total resistance and friction are known.

$$
C_{F}=0.075 /(\log \operatorname{Re}-2)^{2}
$$

The multihull will not be separated from the interference factors IF generated by each hull, which it was a very strong influence on the total resistance especially at high speed. The interference can be approximated by standard eq. (5) or (6).

$$
\begin{gathered}
I F=\frac{R_{\text {Tpenta }}-\left(R_{\text {Tmain }}+2 R_{\text {Tfront }}+2_{\text {Tafter }}\right)}{\left(R_{\text {Tmain }}+2 R_{\text {Tfront }}+2_{\text {Tafter }}\right)} \\
\Delta C_{T}=C_{\text {Tpenta }}-\left(C_{\text {Tmain }}+2 C_{\text {Tfront }}+2 C_{\text {Tafter }}\right)
\end{gathered}
$$

Eq. (5) total resistance pentamaran $R_{\text {Tpenta, mainhull }}$ resistance $R_{\text {Tmain }}$, sidehull resistance in front $R_{\text {Tfront }}$ and after $\mathrm{R}_{\text {Tafter }}$. And Eq. (6) $\Delta \mathrm{C}_{\mathrm{T}}$, interference resistance coefficient which results from subtraction the total resistance as a pentamaran $\mathrm{C}_{\text {Tpenta }}$ to the sum of resistance coefficient of mainhull $\mathrm{C}_{\text {Tmain, }}$ sum of total resistance coefficient of sidehull in front $\mathrm{C}_{\text {Tfront }}$ and sum of total resistance coefficient of sidehull in after $\mathrm{C}_{\text {Tafter }}$.

According to [15] that the interference factor ideally is a negative value. Percentage interference can be expressed in Eq. (7). Negative percentage interference indicates the resistance of the pentamaran was less than the each of hull as separately and summed.

$$
\% C_{T}=\frac{C_{\text {Tpenta }}-\left(C_{\text {Tmain }}+2 C_{\text {Tfront }}+2 C_{\text {Tafter }}\right)}{C_{\text {Tpenta }}}
$$

About trim was more affected by the side-hull position even if its position closer to the main hull. The nondimensional calculate for trim using [16].

$$
\text { Trim }=-\left(\Delta Z_{\text {bow }}-\Delta Z_{\text {stern }}\right) 2 g / V^{2}
$$

where g, gravity in $\mathrm{m} / \mathrm{s}^{2}, \mathrm{~V}$, velocity in $\mathrm{m} / \mathrm{s}, \Delta \mathrm{Zb}_{\mathrm{ow}}$, $\Delta$ Zstern are variation in free model of bow draft (m) and and stern draft $(\mathrm{m})$ respectively.

\section{Experimental Results}

\subsection{Pentamaran with transom (WT)}

Experimental results of resistance components of all configuration pentamaran with transom (WT) versus Fn are plotted in figure $3-5$.

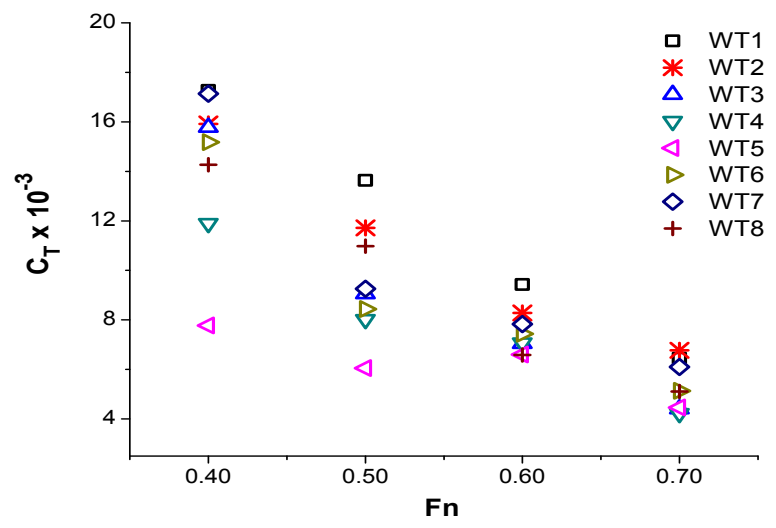

Fig.4. Results of total resistance coefficients $\mathrm{C}_{\mathrm{T}}$ of pentamaran with transom (WT)

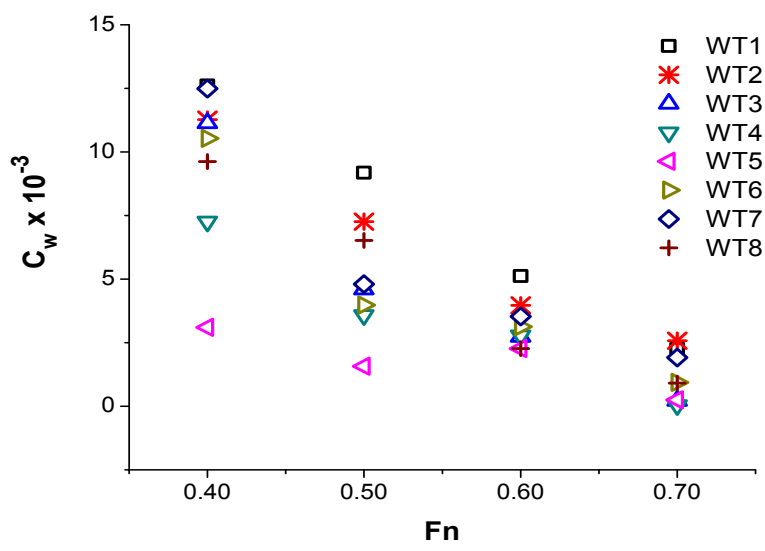

Fig.5. Results of wave resistance coefficients $C_{W}$ of pentamaran with transom (WT)

Corresponding author: yanuar@eng.ui.ac.id 
It can be observed that the best configuration with the lowest resistance are model WT4, stagger $0.35 \mathrm{~L}$ and clearance 1.5B (Fig. 4). The experiment results of $\mathrm{CW}$ (Fig. 5) and IF (Fig. 6) give similar trend with the coefficient of total resistance $\mathrm{C}_{\mathrm{T}}$, and model WT4 still the best result. But model WT5 also shows lower results at Fn 0.7, although for Fn 0.4-0.5 they have significant differences.

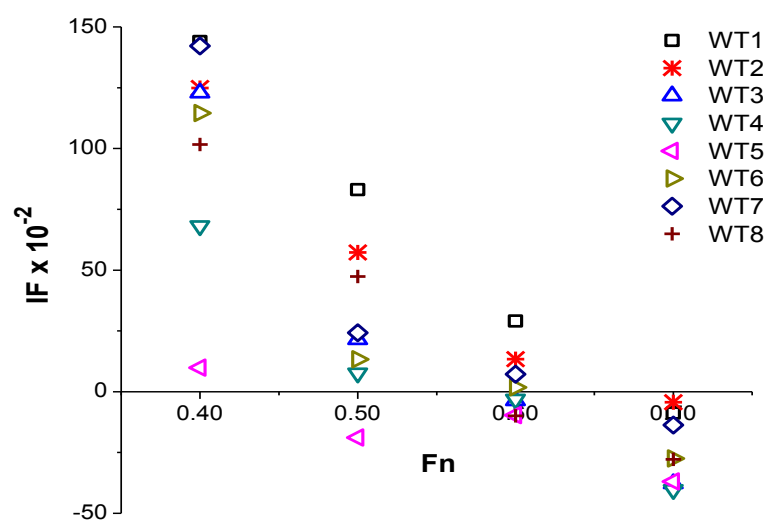

Fig.6. Results of IF of pentamaran with transom (WT)

\subsection{Pentamaran no transom (NT)}

The results of resistance components of all configuration pentamaran no transom (NT) are shown in figure 7 -9.

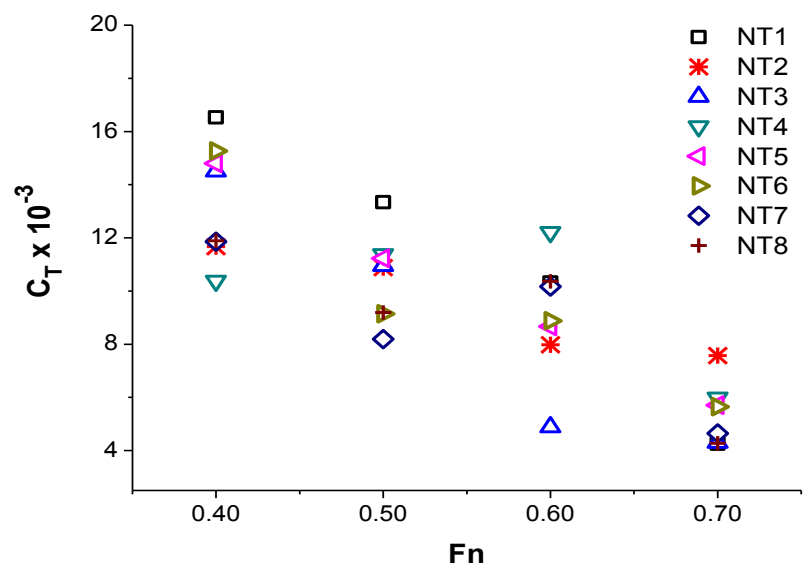

Fig.7. Results of $\mathrm{C}_{\mathrm{T}}$ of pentamaran no transom (NT)

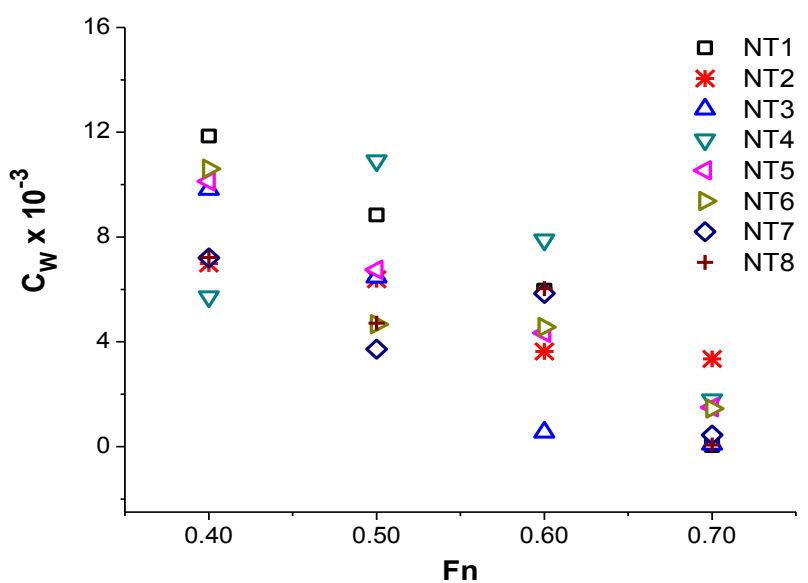

Fig.8. Results of $C_{W}$ of pentamaran no transom (NT)

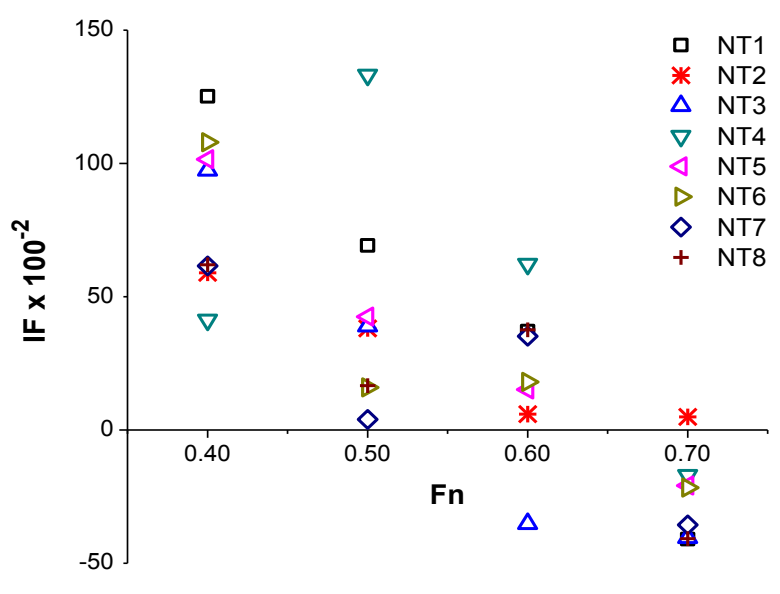

Fig.9. Results of IF of pentamaran no transom (NT)

It can be seen the longitudinal location of the side hulls affects the total resistance coefficient much more than clearance. The total resistance in Figure 7 shows that NT 4 (stagger $0.35 \mathrm{~L}$. clearance 1.5B) and NT 7 (stagger $0.4 \mathrm{~L}$. clearance $1.35 \mathrm{~B}$ ) has the least resistance at $\mathrm{Fn} \leq$ 0.5 , which indicates that the best width can be minimize wave and reduction of total resistance. The best resistance (minimum resistance) for NT models are generated by model NT3, stagger $0.35 \mathrm{~L}$ and clearance 1.35B (Fig. $7-8$ ), although at Fn 0.5 it not the lowest result.

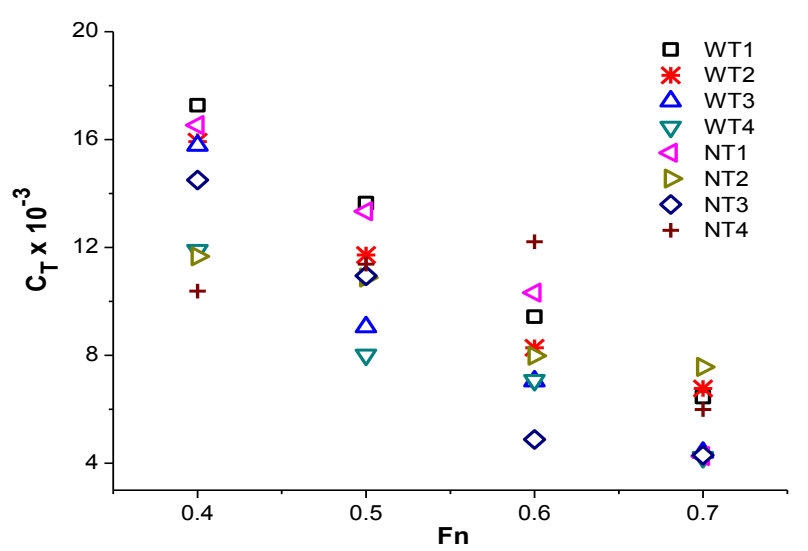

Fig.10. Comparison between WT and NT on stagger $0.35 \mathrm{~L}$

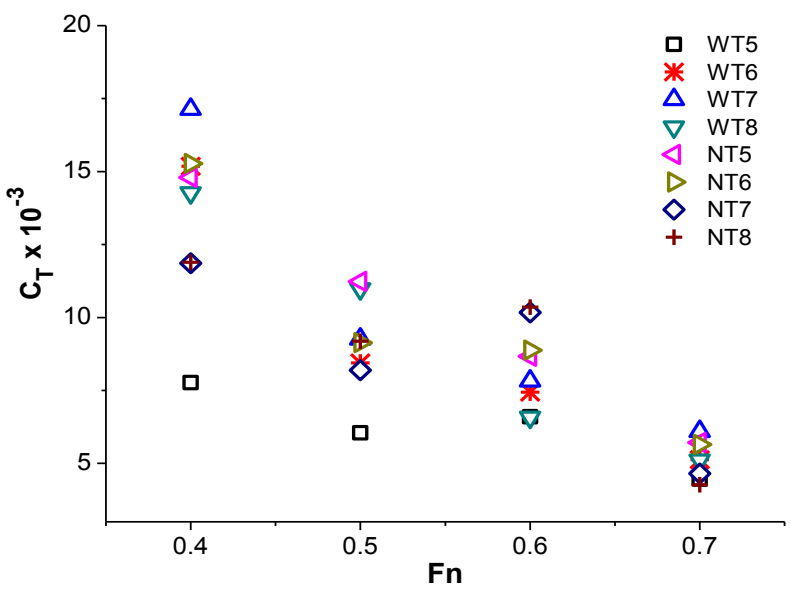

Fig.11. Comparison between WT and NT on stagger 0.4L 
The interference factor IF as shown in Fig. 9 that some of models have a negative interference for $\mathrm{Fn}>$ 0,5 , which is beneficial to resistance. Therefore, it can be a destructive interaction of an individually wave system. And the best results of IF were generated by NT 3 (stagger 0.35L. clearance 1.55B) and NT 7 (stagger $0.4 \mathrm{~L}$. clearance $1.35 \mathrm{~B})$.

The comparation results of WT and NT model for all the configurations are shown in figures 10 (stagger $0.35 \mathrm{~L}$ ) and 11 (stagger $0.4 \mathrm{~L}$ ). It can be seen for stagger $0.35 \mathrm{~L}$ at high speed NT model give less resistance than WT model. And with increase of stagger $(0.35 \mathrm{~L}$ to $0.4 \mathrm{~L})$ NT still the lowest resistance than WT model. This indicates there was a strong effect of transom for slender hulls in particular at high speed which beneficial to reduce resistance.

\subsection{Trim}

Results regarding trim angle for WT and NT are plotted in figure 12-13.

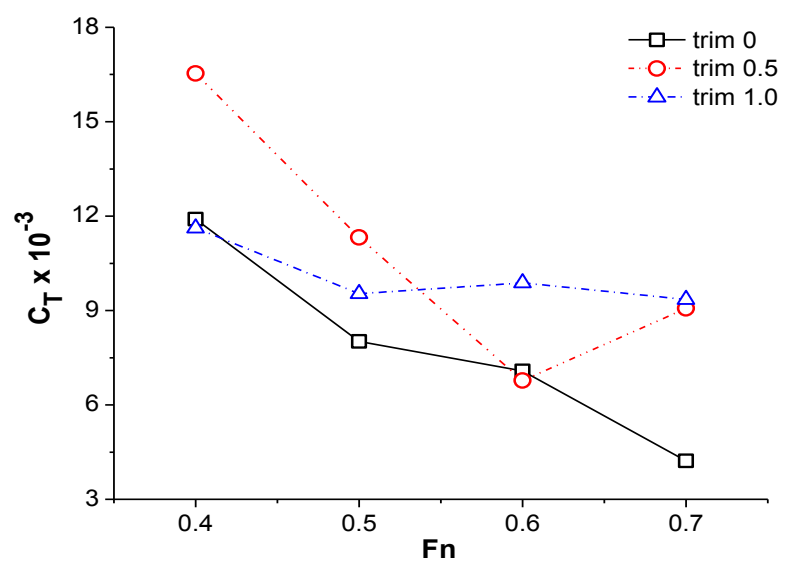

Fig.12. Trim results of WT model

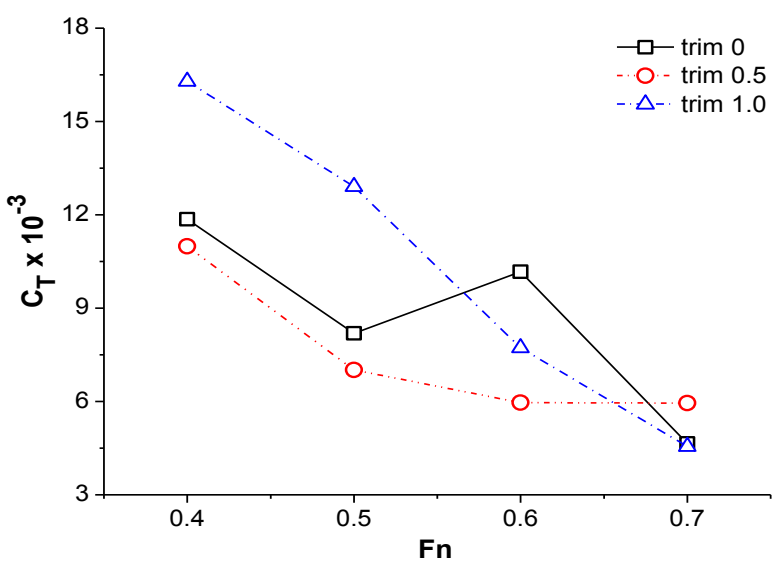

Fig.13. Trim results of NT model

The running trims was done with trim angle on $0^{\circ}$; $0,5^{\circ} ; 1,0^{\circ}$ for all configurations after gets the best configuration of stagger and clearance. Shown in Fig. 12 was a WT 4 model that the trim angles for all conditions get reduction as increasing Fn. But on trim angle 0.5 has extremely changed on total resistance at Fn 0.7. Fig. 13 was trim results of NT7 model shows favorable for resistance results on trim angle 0.5 and 1.0 specifically for high speed. Although on displacement condition give unfavorable at Fn 0.6.

\section{Conclusions}

A comprehensive experimental campaign has been performed to hydrodynamic analysis of trimaranpentamaran with stern variations. It has been observed that: hydrodynamic of of trimaran - pentamaran strongly depends on the side hull longitudinal location (stagger) besides of transom stern; transom stern (WT model) well at low and high-speed but performs poorly in the intermediate speeds of $\mathrm{Fn}=0.4$ to 0.5 in particular on stagger $0.35 \mathrm{~L}$ and clearance $1.05 \mathrm{~B}$; non-transom stern (NT model) also well at low and high-speed ranges, moreover give beneficial resistance than WT model. It well at most of the speeds higher than Fn 0.5; the interference factor IF of both WT and NT have a negative interference for $\mathrm{Fn}>0.5$. The best results for WT was generated by WT4, stagger $0.35 \mathrm{~L}$ and clearance 1.5B. Furthermore, for model non-transom was generated by NT 3 (stagger $0.35 \mathrm{~L}$. clearance $1.55 \mathrm{~B}$ ) and NT 7 (stagger $0.4 \mathrm{~L}$. clearance $1.35 \mathrm{~B}$ ); and trim condition more favorable for NT model than WT on trim angle 0.5 and 1.0 specifically for high speed. It is off course depending on position of side hull to main hull.

Some work must be still dedicated to defining some criteria to a be able to consider as additional on shape of the hulls and side hull positions.

This work has been financially supported by by PITTA Grant 2018 funded by DRPM Universitas Indonesia with no. 2562/UN2.R3.1/HKP.05.00/2018. The authors wish to appreciation for the valuable support from pentamaran team of Department of Mechanical Engineering.

\section{References}

1. Oller, Erik, Vasilios Nikou, \& Konstantinos Psallidas. Focused Mission High Speed Combatant. DTIC Document (2003)

2. Ikeda, Yoshiho, Emiko Nakabayashi, and Ai Ito. Concept design of a pentamaran type fast RoRo by PITTA Grant 2018 funded by DRPM Universitas Indonesia with no. 5000/UN2.R3.1/HKP.05.00/2018Eng. 1:35-42 (2005)

3. Doctors, L.J. and Scrace, R.J. The Optimisation of Trimaran Sidehull Position for Minimum Resistance. FAST03, Ischia, Italy (2003)

4. Molland, A., Wilson, P., Taunton, D., Chandraprabha, S., Ghani, P. Resistance and wash measurements on a series of high speed displacement monohull and catamaran forms in shallow water. Int. J. of Mar.Eng. 146, 19-38 (2004)

5. Broglia, R., Zaghi, S., Di Mascio, A. Numerical simulation of interference effects for a high-speed catamaran. J. Mar. Sci. Technol. 16, 254-269 (2011) 
6. Peng, Hongxuan. Numerical computation of multihull ship resistance and motion, Dalhousie University Halifax (2001)

7. Yanuar, Gunawan, $\mathrm{M}$ A Talahatu, Ragil $\mathrm{T}$ Indrawati, and A Jamaluddin. Resistance analysis of unsymmetrical trimaran model with outboard sidehulls configuration, J. of Marine Science and Appl. 12, Issue 3, 293-297 (2013)

8. Yanuar, Gunawan, Kurniawan T. Waskito, and A. Jamaluddin. Experimental Study Resistances of Asymmetrical PentamaranModel with Separation and Staggered Hull Variation of InnerSide-hulls, Int. J. of Fluid Mech. Research (2015).

9. Yanuar, Gunawan A. Muhyi A. Jamaluddin. Ship resistance of quadramaran with various hull position configurations. J. of Marine Science and Appl. 15. Issue 1. 28-32 (2016)

10. Yanuar, Ibadurrahman, Kurniawan T. Waskito, S. Karim and M. Ichsan. Interference resistance of pentamaran ship model with asymmetric outrigger configurations, J. of Marine Sci. and Appl. 16. Issue 1. 42-47 (2017)

11. Yanuar, Ibadurrahman, M.H Faiz and M.H. Adib. Experimental Analysis of Diamond Pentamaran Model with Symmetric and Asymmetric Hull
Combinations, J. of Eng. and Applied Sci. 12 (13): 3434-3440 (2017)

12. Tuck, EO, DC Scullen, and L Lazauskas. Sea wave pattern evaluation: Citeseer (2002).

13. Molland, A.F., Wellicome, J.F., Couser, P.R. Resistance experiments on a systematic series of high speed displacement catamaran forms: variation of length-displacement ratio and breadth-draught ratio. R. Inst. Nav. Archit. 138, 55-71 (1996)

14. Begovic E., Bove A., Bruzzone D., Caldarella S., Cassella P., Ferrando M., Tincani E., Zotti I. CoOperative Investigation into Resistance of Different Trimaran Hull Forms and Configurations, the 8th Int. Conf. On Fast Marine Transportation, St. Petersburg (2005).

15. Yeung, R.W., Wan, H. Multi-hull configuration design: a framework for powering minimization. In: Proceedings of the ASME 2007 26th International Conference on Offshore Mechanics and Arctic Engineering (OMAE2007). 4. 833-842 (2007)

16. Kim, Y.H., Jenkins, D. Trim and Sinkage Effects on Wave Resistance with Series 60; $c b=0.60$. Technical report. David W. Taylor Naval Ship Research and Development Center, Bethesda, Maryland (1981) 